\title{
An industrial oriented workflow for 3D printed, patient specific orthopedic cast
}

\author{
Mario Formisano $^{1} \cdot$ Luigi luppariello $^{2}$ (D) Antonio Casaburi ${ }^{2} \cdot$ Pasquale Guida $^{2}$ (D) $\cdot$ Fabrizio Clemente ${ }^{1,3}$ (D)
}

Received: 15 May 2021 / Accepted: 27 July 2021

Published online: 07 October 2021

(c) The Author(s) $2021 \quad$ OPEN

\begin{abstract}
The clinical use of 3D printed patient specific orthopaedic cast is of wide interest. However, design and production have problems such as production time, which can take up to $35 \mathrm{~h}$, and standardized procedure considering that there are medical devices that must comply mandatory and/or voluntary standards. Moreover, the proposed procedures do not fully consider the traceability of this innovative medical device design to comply with standards and industrial proposes. The aim of this work is to propose a semi-automatic workflow for the production of the 3D printed orthopaedic casts. The procedure is oriented towards a reduction time in different phases (as scan setting, designing technique, printing orientation) of the production flow. The workflow is compliant with recognized quality standards for the production of additive manufactured medical devices. This approach offers the possibility to introduce new 3D printed medical devices in clinical practice as well as to design an optimized industrial workflow.
\end{abstract}

Keywords Plaster cast · Medical device · Computer-aided design · Additive manufacturing $\cdot$ Clinical application

\section{Introduction}

The treatment of forearm fractures involves immobilizing the limb for about 3 to 4 weeks. The limb is usually immobilized mainly with plaster cast and rarely with splints or braces which can be uncomfortable, particularly during the summer. Patient satisfaction using plaster cast is poor [1] due to the physical characteristics of this old medical device. To overcome this drawback, the use of computeraided design (CAD) and 3D printing technology to produce personalized plastic casts, have been largely proposed [1-5] increasing the public awareness in the clinical use of these low cost and widely available technologies.

The advantage of these devices is largely recognized in reducing discomforts in the use of the arm due to the lightweight and removability, as well as giving benefits in daily living activities of patients (especially for frail people) allowing ventilation inside the cast and the possibility of a normal hygiene due to the waterproof nature of the plastic used materials. This enhances patient satisfaction levels [6-8].

Previous studies have demonstrated the feasibility of the clinical use of orthopaedic personalized 3D printed cast for the treatment of forearm fractures in paediatric patients [5]. Thus, in daily clinical activities, it is necessary to implement a production phase compliant with time required by clinical course, less than $24 / 36 \mathrm{~h}$ from trauma.

Actually, real clinical application of this innovative devices is limited due to both the difficulties for medical practitioners to scan and produce anatomical models [1] as well as the time required to produce cast in a time useful to be provided in daily clinical use (up to $35 \mathrm{~h}$ [4]).

At the best of our knowledge, in current literature there are reference to practical implementation of Digitized

Fabrizio Clemente, clemente@ic.cnr.it | ${ }^{1}$ Institute of Cristallography, National Research Council (IC-CNR), Rome, Italy. ${ }^{2}$ Santobono Pausilipon National Children's Hospital, Naples, Italy. ${ }^{3}$ Santobono Pausilipon Foundation, Naples, Italy.

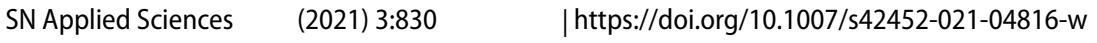


Splinting Process (DSP) neither in clinical practices nor in industrial applications [1, 2]. Moreover no one has still faced the problem of traceability of the final product, as suggested both from FDA [9], ISO [10] and innovative industrial process $[11,12]$ in a qualified medical device manufacturing.

Actually, most of methodologies described in literature neither guarantee the achievement of a standardized workflow to be applied for industrial or clinical daily applications nor allow an easily usable, verified and scalable production framework $[1,2,13-17]$.

Technical studies $[15,16]$ reports few examples. [3] introduce a workflow based on a manual procedure and $[1,2]$ design an automatic or semiautomatic procedure.

In [5] is showed the implementation of a production line inside a hospital even if slow and fully empirical. The aim of this work was to develop, a semi-automatic workflow for the fused deposition modelling (FDM) 3D-printed orthopaedic casts to be introduced according to [9-11] both in clinical and in industrial environment to promote the real use of this innovative medical device.

The study is focused on two main aspects: time saving and compliance with recognized standard to implement a quality system.

\section{Materials and methods}

\subsection{Clinical background}

Distal radius fracture (wrist fracture without complication) management usually includes immobilization with plaster cast, splint, or molded synthetic material cast to immobilize the injured upper extremity $[18,19]$. A normal course of the treatment includes the application of an immobilizer and follow-up of 4-5 weeks [19-21]. Maintaining plaster cast clean and dry is difficult and the risk of infection increases. Poor ventilation and an improper fit also cause discomfort and complications such as cutaneous diseases, bone and joint injuries, or malunion [15, 15, 19, 22]. As a matter of facts, the rate of cast-related complications published is high with up to $31 \%$ being reported in published studies [23].

As said, first clinical experience [5] demonstrated the feasibility of treatment of paediatric patients, affected by greenstick fracture of forearm, with 3D printed orthosis. Each cast was designed manually by an expert "user", starting from a 3D scan of the limb. During this study the cast design and manufacturing required up to $24 \mathrm{~h}$. This represented a limit to introduce this new device in the clinical course.

In the following are reported the improvements in the production process for $3 \mathrm{D}$ printed cast, compared to the original (manual) approach [5], which led to a semiautomatic procedure and a traceable workflow in order to obtain a qualified medical device.

\subsection{Scan procedure}

Data acquisition is the first step of DSP. The quality and accuracy of the scan of the patient's affected limb plays a critical role in determining the success rate of the split model subsequently designed.

In the feasibility study 3D scan of the arm is obtained with a low-cost scanner like the 3D Systems ${ }^{\circledR}$ Sense $^{\circledR}$ with depth resolution of $0.5 \mathrm{~mm}$ sufficient for subsequent elaborations with the best cost-performance ratio. It remains the same from its initial definition even improved with practical tricks. A written procedure which includes mandatory features and tips. In this phase scan precautions such as medium intensity white light (like during a cloudy day), white walls room, proper scan resolution setting, thumb outstretched and right palm orientation have been introduced. The patient must be placed sit with the injured arm raised, fingers fixed with finger trap at rod.

As recommended by FDA [9], anthropometric parameters, e.g., circumference length, hand, wrist and elbow, must be measured with a tape measure and reported in a proper form in order to mitigate possible measurement errors and to verify the goodness of the scanning process. The final procedure accept scan with less than $\pm 3 \mathrm{~mm}$ difference between the real arm measurements results. The 3D model which is exported as a mesh in.obj format.

\subsection{Manual procedure and improvement requirements}

All the choices about design were arbitrary and model specific, and also difficult to report. The design process required about two hours. The cast were designed to immobilize the wrist from the hand to the elbow, leaving the fingers and thumb free. Original manual procedure from [5] consisted of several steps (Fig. 1), deep knowledge of CAD software (SW) (i.e. Rhinoceros ${ }^{\circledR}$ ) and great interaction with the user. As in column A of Fig. 1, all unnecessary parts (arm, fingers and thumb) must be removed (Fig. 1A.1). All the possible holes and defects were also removed using the Fill Holes command (Fig. 1-A.2). The surface was enlarged with an offset of $0.5 \mathrm{~mm}$ (Fig. 1-A.4) to create a distance from the skin. Then the volume of the cast was created with a thickness of $4 \mathrm{~mm}$ using the Shell command (Fig. 1-A.5). Thus, cast was divided in two parts by a plane (Fig. 1-A.6). The holes pattern was created manually by Boolean subtraction with several cylinders (Fig. 1-A.7). Internal and external closing stops were added (Fig. 1-A.8). 
Fig. 1 General processing Workflow: A Manual procedure; B Semi-automatic procedure

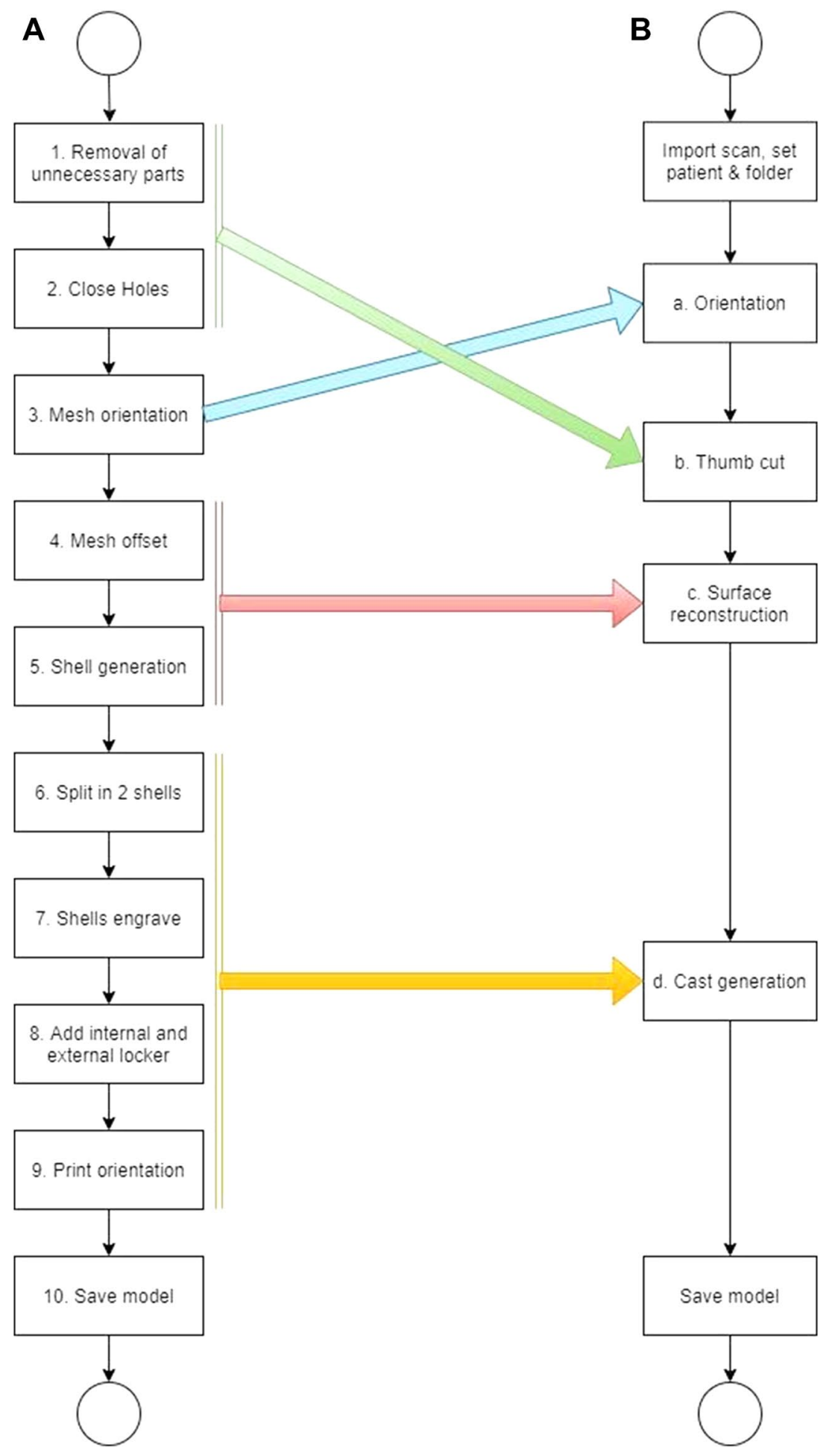

Then, the two shells were arbitrarily rotated of about $25^{\circ}$ in order to optimize the supports and reduce printing time.

Furthermore, the reconstruction of the surface, punch holes distribution and the alignment of the closing stops are carried out each time. Thus, process traceability, designing times, CAD operations, and production time are uncertain. 


\subsection{Design of semiautomatic procedure and user interface}

The semiautomatic procedure has been developed in Grasshopper ${ }^{\circledast}$, a Rhinoceros ${ }^{\circledR}$ plug-in. Grasshopper ${ }^{\circledR}$, is a graphic programming SW that implements the Rhinoceros ${ }^{\circledR}$ functionalities within its working environment, allowing to create programs in the form of operational sequences of single blocks.

In Grasshopper ${ }^{\circledast}$ the user acts on a window containing alphanumeric input/output, Boolean switch, number slider, knobs, Boolean operators, etc. to realize algorithmic sequences. The developed algorithm acts simultaneously on a second graphical interface in the Rhinoceros ${ }^{\circledR}$ workspace.

Moving in this new workspace the manual intuitive phases must be converted in a flow chart of subsequent operation. To this the workflow from Fig. 1.A moves to that reported in Fig. 1.B to exploit Rhinoceros ${ }^{\circledR}$ tools capabilities.

Moreover, in order to obtain a robust and traceable process, the whole procedure, including post processing and testing (not treated in this paper) are referred to Technical Considerations for Additive Manufactured Medical Devices from FDA [9]. (Fig. 2) Besides, Fig. 3 introduces the user interface in Grasshopper ${ }^{\circledast}$, where the correspondence to the different phases from Fig. 1.B are highlighted in Unified Modelling Language (UML) activity diagram (Fig. 4). where the different phases are reported into the pools with the pool containing the actions required to the user.

Following a user-oriented approach, all functional blocks are hidden to user and will be duly described in the next sections. This interface allows also to less-experienced users to produce a functional cast. Furthermore, each parameter defined by user during the process is stored in the program and saved in a report file, generated together with the cast file at the end of processing. This is for the traceability of the process [12].

\subsection{Grasshopper ${ }^{\circledast}$ workflow}

The design procedure (Fig. 4) shows the user pool, and the related actions with other pools according to Fig. 1.B.
The user, after a preliminary opening the scan file in Rhinoceros ${ }^{\circledR}$ and the raw extraction of the arm from the whole acquired scan, uses cutting planes and Boolean split command.

Then the user (Fig. 4, Pool u) defines the patient ID and the destination folder of processing in the two yellow Panel on the (top of Fig. 3) and the mesh is uploaded in Grasshopper ${ }^{\circledast}$.

The user must interact with few Number Sliders and activate the section through Toggle switch.

Even some actions in this phase remain manually performed by user, Grasshopper ${ }^{\oplus}$ offers both a reduction time and a fully repeatability.

In the following are exploited the activities performed by the SW according to the UML diagram (Fig. 4) including the interactions with user (Pool u).

\subsubsection{Pool. a: Orientation}

The use of a procedural algorithm requires to fix the origin of the workspace in which the cast must be developed. This is performed in two steps: a fully automatic pre-orientation and a manual fine adjustment. Figure 3a reports the panels used in this phase whereas Fig. 5 shows the correspondent Rhinoceros ${ }^{\circledR}$ workspace.

2.5.1.1 Pre-orientation algorithm The pre-orientation algorithm computes the reference plane using the Principal Component Analysis (PCA) on the cloud composed of the vertices of the mesh (Pool a.1). The reference plane is then used as base plane for the Orient block, while the $\mathrm{XY}$ plane of Rhinoceros ${ }^{\circledR}$ workspace is used as destination.

The Deconstruct mesh block is used to extract the point cloud from the mesh.

PCA computes the principal components of a dataset to perform a change of basis. The point cloud is assumed as the dataset and the first two eigenvectors of covariance matrix represent the two main axis of the reference plane of the mesh (Pool a.2). Eventually the mesh is oriented using Orient block (Pool a.3).

2.5.1.2 Orientation adjustment The pre-orientation algorithm works only on geometrical features of the mesh; thus, the user must fine adjust the orientation specially

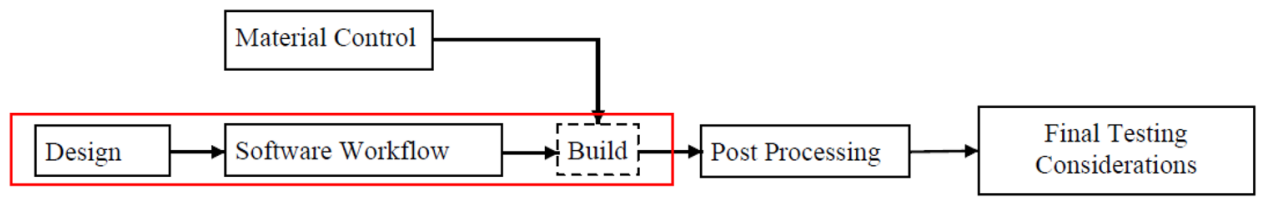

Fig. 2 Technical Considerations for Additive Manufactured Medical Devices main workflow from [9]. Red box put in evidence the phases covered by the semiautomatic procedure 

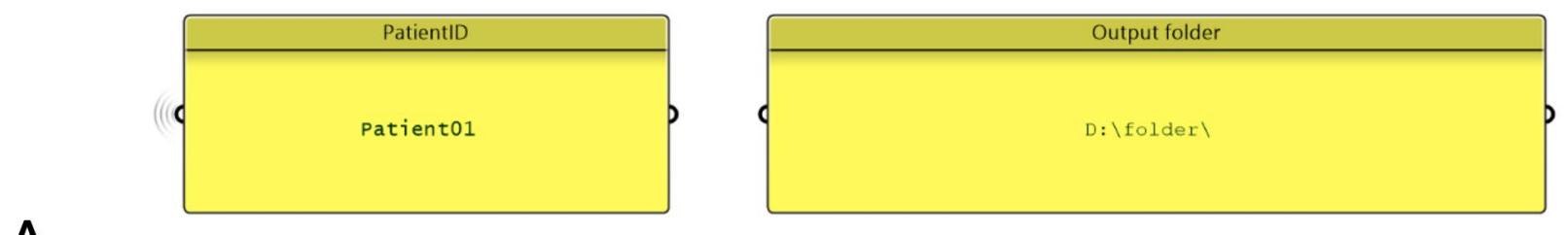

A

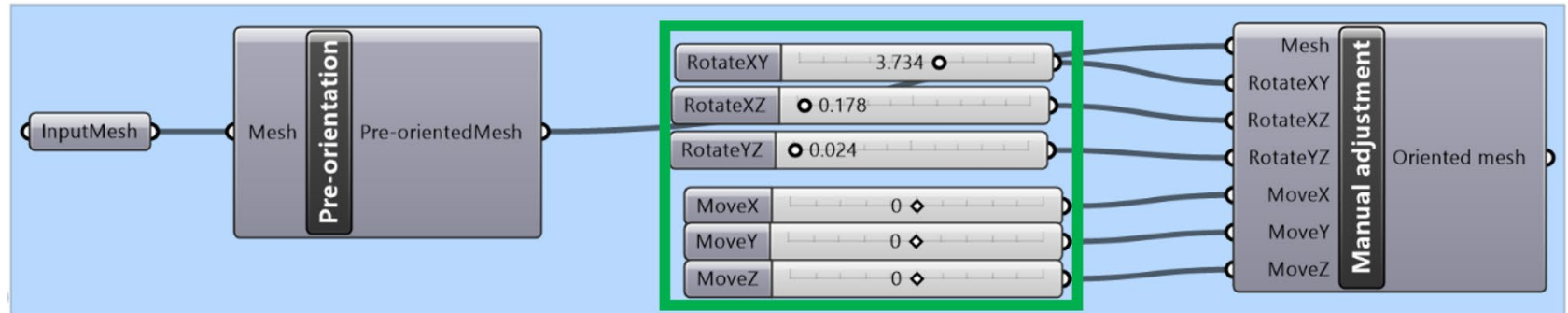

B

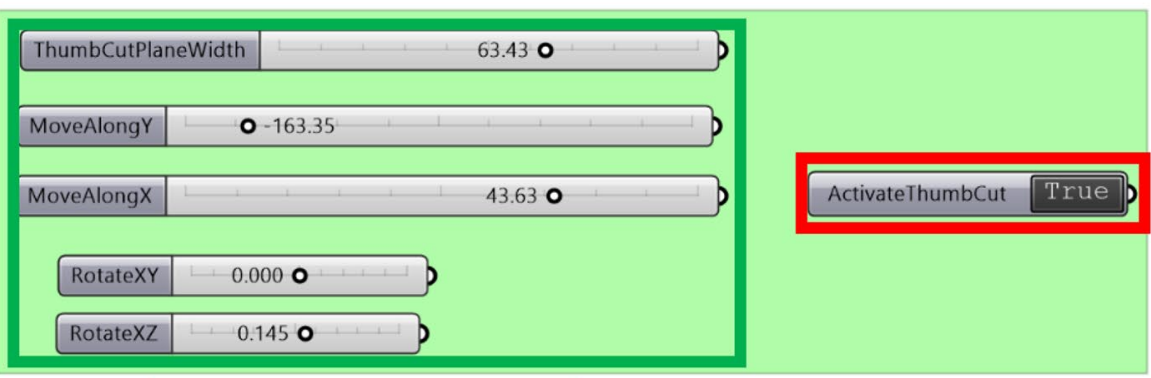

C

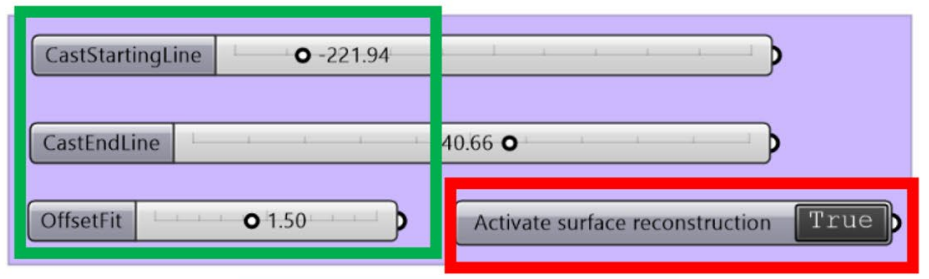

D

Activate Cast production True

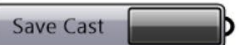

Fig. 3 Grasshopper ${ }^{\circledast}$ User Interface. Blocks refers from a to $\mathbf{d}$ to Fig. 1B; Number Slider in green boxes, Toggle switch in red boxes

to centre thumb (next step). The adjustment (Pool u.3) is performed using 6 Number sliders (Fig. 3a) 3 for rotation and 3 for translation.

\subsubsection{Pool. b: Thumb cut}

Thumb recognition allows creating the hole for the patient's thumb, and fixing its position for the subsequent processing steps. It is a critical step for final patient comfort. The user places a cutting plane through the thumb volume. The dimension and position of the plane are set via 5 number sliders (Fig. $3 b$ ) that define respectively plane width, position along $X$ and $Y$ axis and $X Y$ and $X Z$ rotation. Figure 6 shows the final positioning of cutting plane activated with toggle switch (Pool u.5) of the panel to pass to the next step.

With reference to Fig. 3 in (Table 1) the time saved in the above-described phases are reported and compared with manual procedure from [5].

Moreover, it is to put in evidence that all set are recorded in the file record of the device in order to retreat the $X Y Z$ distribution of the cast in the case of fail (total or partially) of successive phases (see later on).

\subsubsection{Pool. c: Cast surface reconstruction}

Last interaction for the creation of the cast volume surface requires to cut the mesh at start and end point of the cast. Then, an offset between inner cast surface and patient skin 


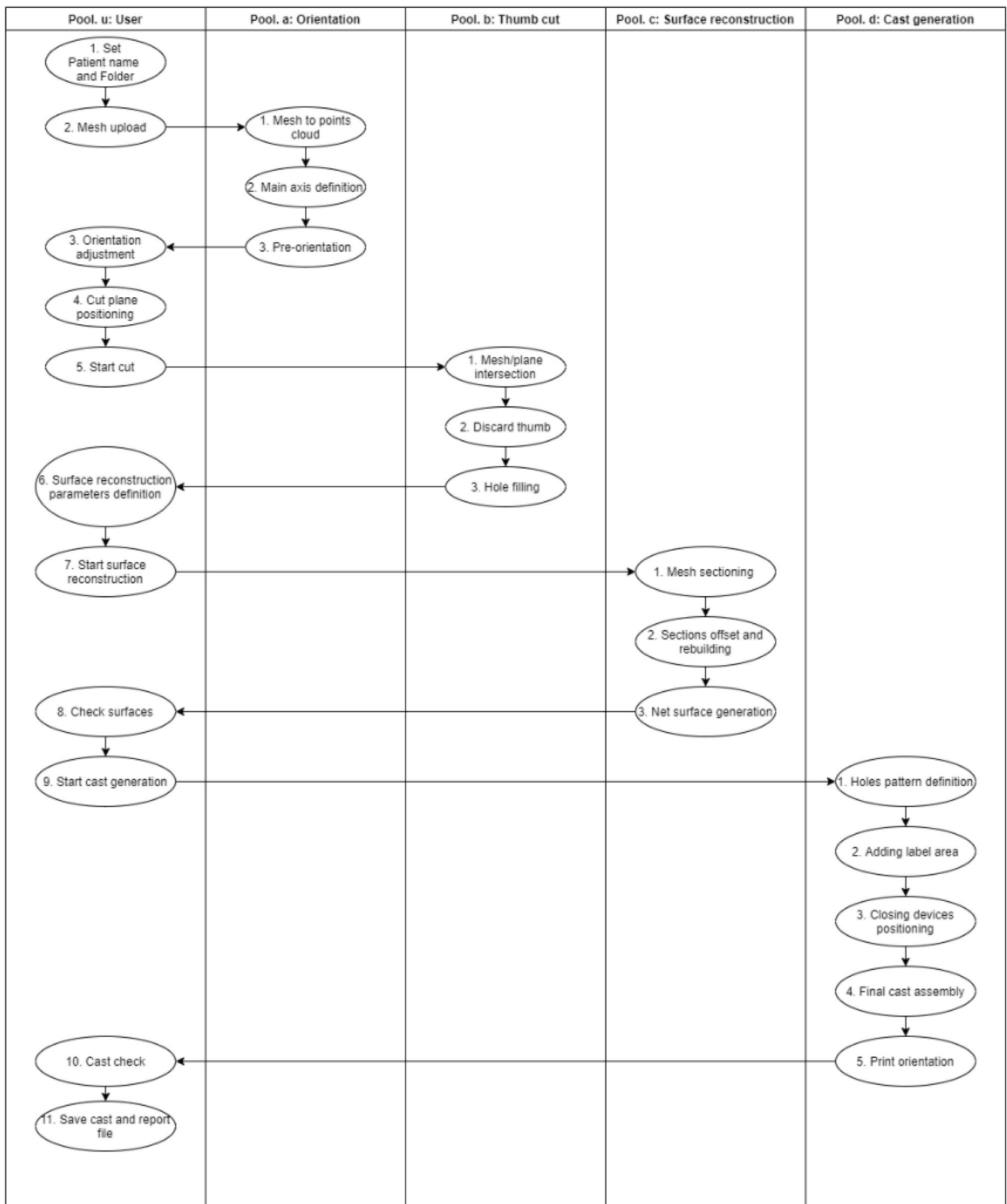

Fig. 4 Full Grasshopper ${ }^{\oplus}$ processing UML: description of activities sequence in Grasshopper

must be introduced due to patient different muscular tone according to anthropometric measurements acquired during the scan session (Fig. 3c).
After that, the surface reconstruction is demanded to the SW procedure.

The SW generates different sections each $5 \mathrm{~mm}$ (Pool c.1) avoiding bad acquisition volumes where the

\section{SN Applied Sciences}




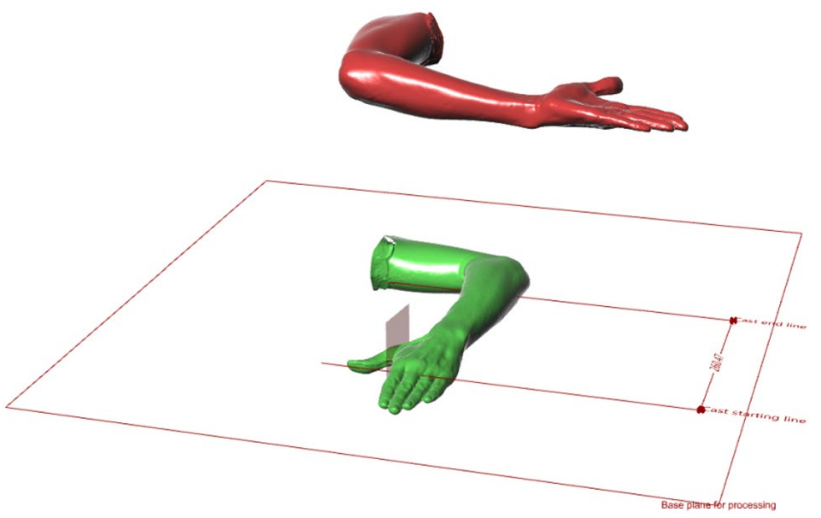

Fig. 5 Preorientation Rhinoceros panel: On upper side (in red) the original mesh of the forearm randomly oriented; on lower side (in green) the mesh oriented and the referenced XY plane

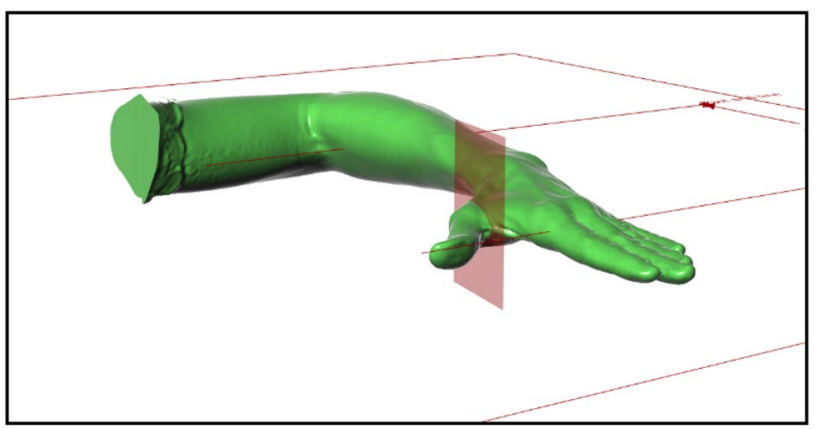

Fig. 6 Thumb cut plane positioning

reconstructed sections are $<50 \mathrm{~mm}$ and algebraic sections using 32 points and a third-grade polynomial imposing an offset from the skin as defined by the user (Pool c.2).

Then the inner cast surface and the outer with $4 \mathrm{~mm}$ offset from the first (Pool c.3) are produced. The surfaces are joined to create a CAD volume and divided in two shells. The user can compare the generated volume with the scanned mesh to check the fitting and patient comfort (Fig. 7).

\subsubsection{Pool. d: Cast generation algorithm}

After the activation of last Toggle switch from Fig. 3.d, the rest of process do not require any user interaction.

SW executes three phases from the first manual process: Holes pattern definition, Internal and external closing points positioning and Print orientation (as from Fig. 1.A) which are here grouped in a single block (as from Fig. 1B) described in the following.

2.5.4.1 Pool d.1: Holes pattern definition Shell is considered as a grill of holes (rectangular in the first approach) (Fig. 8a).

Surfaces to be pierced are defined imposing minimal hole distance of: (i) $8 \mathrm{~mm}$ from lateral edge of the shell and (ii) $15 \mathrm{~mm}$ from shell's end point. The distance between holes is imposed almost $4 \mathrm{~mm}$. Due to the characteristic of Grasshoper ${ }^{\circledast}$, hole pattern is obtained testing the distribution along the shells of 10-22 mm diameter (step $1 \mathrm{~mm}$ ) holes with the above mechanical constrains.

The goal is to maximize the open section of the device. Then the rectangles are converted in ellipses (Fig. 8b).

It is to put in evidence that the constrains of this section include mechanical properties of the material. Such parameters are from mechanical study not reported here and from practical experience.

2.5.4.2 Pool d.3: Internal and external closing points Fasteners (Fig. 9B) and internal stops (Fig. 9C) are required to guarantee a good stability during use. The first ones have a standard dimension and are positioned along the border curves in standard intervals computed according to the length of the device. Internal stops are pin-hole couple inserted to follows the border shape avoiding intersection between the hollow part and the external surface.

All these operations are SW performed (Pool d.4).

A slot is added for the label application to refer the device (Pool d.2).

2.5.4.3 Pool d.5: Print orientation The two shell's models are oriented horizontally with an angle of $50^{\circ}$ on $\mathrm{YZ}$ plane to ensure the best performance in terms of material con-
Table 1 Pre-processing phases timing comparison (ref. Fig. 1).

\begin{tabular}{llll}
\hline Manual procedure A & Timing (mm:ss) & Semiautomatic Procedure B & Timing (mm:ss) \\
\hline $\begin{array}{l}\text { Unnecessary parts removal } \\
\text { including thumb (A.1) }\end{array}$ & $05: 00$ & Thumb cut (B.b) & $00: 05^{*}$ \\
Close holes (A.2) & $03: 00$ & & \\
Mesh orientation (A.3) & $03: 00$ & Orientation (B.a) & $00: 05^{*}$ \\
Total processing time & $11: 00$ & Total processing time & $00: 10$ \\
\hline
\end{tabular}

( ${ }^{*}$ fine adjustment requiring less than $10 \mathrm{~s}$ ) 


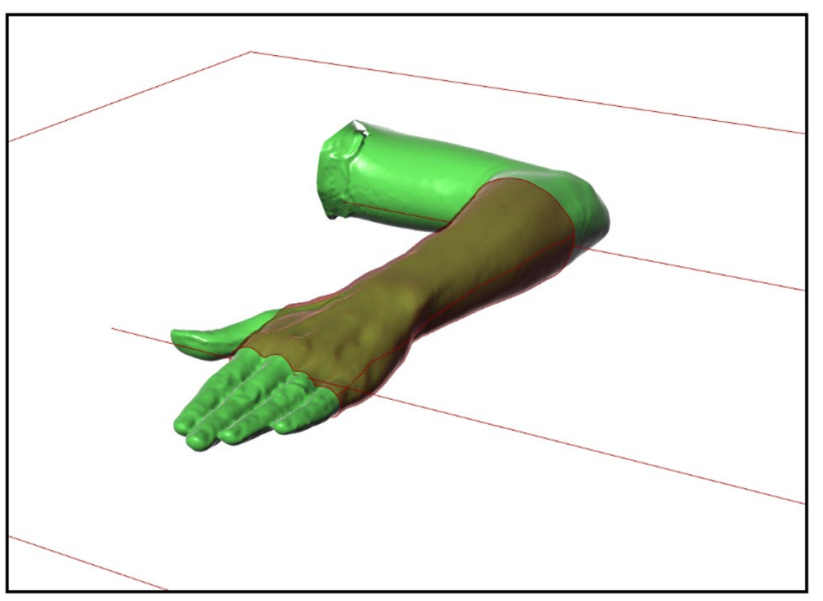

Fig. 7 Cast surface reconstruction and comparison with acquired volume

suming, preservation of internal stops and printing time saving. (See later).

Then the shells are moved on the XY plane and their orientation, according to $\mathrm{YZ}$ plane is correct to minimize supports volume. After checking the model, it is possible to save the models and the report file. The cast model is kept and stored in.stl format as recommended by considerations of FDA [9]. In the Fig. 10 an example of automatic model placing is reported. The table below (Table.2, 3) shows timing comparison with manual procedure as from [5] using the same notation from Fig. 1.

\subsection{Print setting and time saved in printing}

After design the real bottleneck for clinical use of this innovative devices is printing time. Actually, printing is the most expensive part in terms of time, and a good optimization must be directed towards both piece orientation and printing settings. A good orientation has to provide the reduction of support material and printing time and ensure piece strength. Different authors proposed several algorithms for orientation optimization [16, 24], but this is not the purpose of this work. We choose an iterative method comparing time and support material usage, between various orientation. As shown in Fig. 11, we chose the horizontal direction as the main direction, then we found the best angle for each shell, performing simulation every $10^{\circ}$, using Ideamaker ${ }^{\circledR}$ slicer. Other improvements affect printing setting, above all the enlargement of nozzle from standard 0.4 to $0.8 \mathrm{~mm}$ and set the layer height to $0.4 \mathrm{~mm}$, which after several test does not show any notable losing of resolution. The material used is Zortrax Z-UltraT, while printing parameters are: number of loops $=3$; infill $=5 \%$; support overhang angle $=45^{\circ}$; support

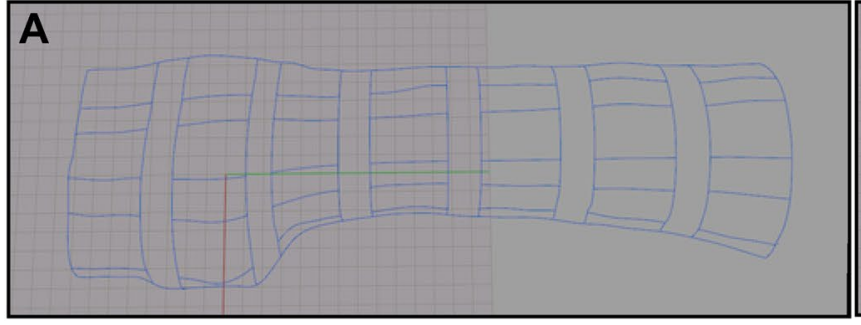

B

Fig. 8 Holes pattern: A Starting squared grid; B Circular holes

Fig. 9 Upper shell fully assembled: A-label slot; B-fastener; $\mathbf{C}$-Pin-hole detail

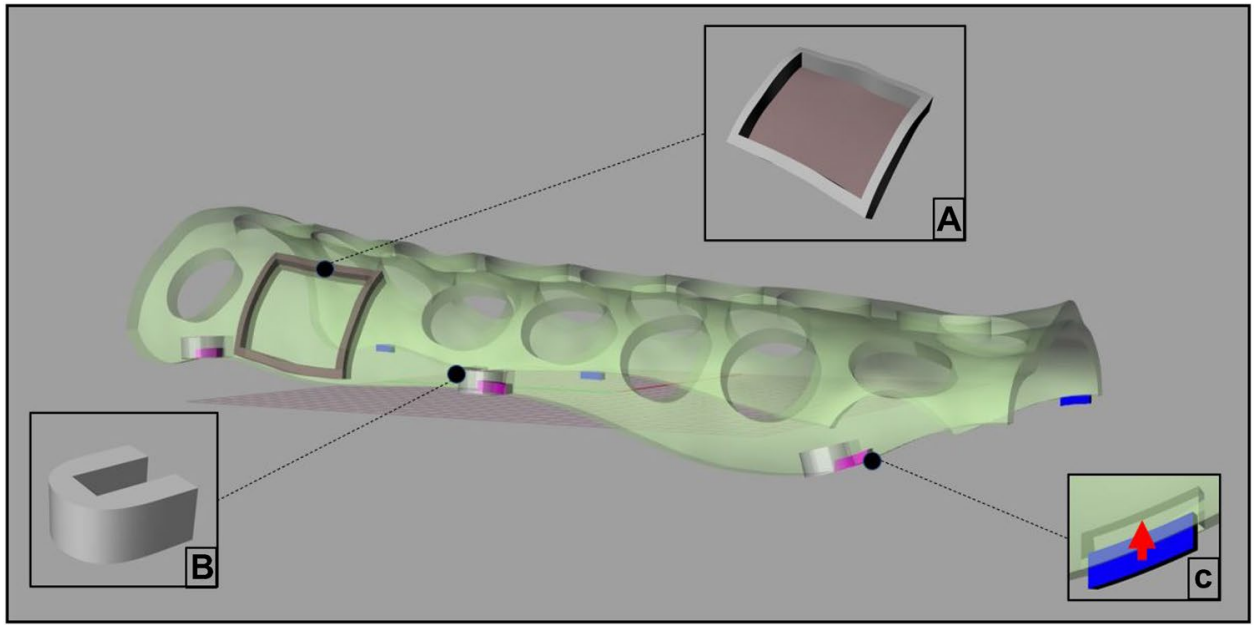




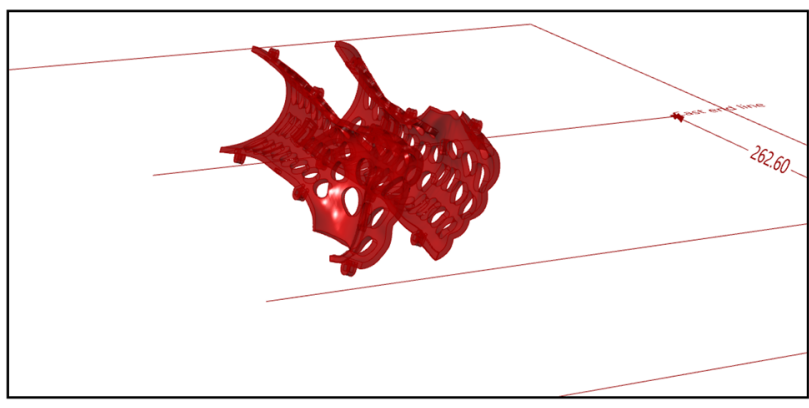

Fig. 10 Automatic print orientation algorithm result

infill ratio $=10 \%$; raft type $=$ grid; bed temperature: $95^{\circ} \mathrm{C}$; nozzle temperature $=245^{\circ} \mathrm{C}$; printing speed $=55 \mathrm{~mm} / \mathrm{s}$.

In Table 3 there are presented the results of slicing simulations for a single shell. On the left there are the simulations for the $0.4 \mathrm{~mm}$ nozzle and on the right the $0.8 \mathrm{~mm}$ nozzle. Among these simulations, we choose $50^{\circ}$ orientation that according our experience could be adapted to any case, both for timing and for print success, because more convenient angles for timing could lead to printing inaccuracies.

\section{Results}

Starting from the 3D scan of the hand-wrist-arm, the proposed procedure is presented as a workflow to produce personalized cast. The final orthopaedic device is composed of two halves. Fixation components on the specific external regions of both shells ensure fastening.

As previously introduced, the main result is the time saving against the manual one experimented in [5]. Elsewhere is reported these needs [1] even using a less userfriendly interface. The introduction of programmed modules which explain each part of the process, reduces both the user operation allowing the utilization of the SW also to medical practitioner with few hours training, and the general time of cast production allowing the production of several casts in less time. Moreover, a correct orientation and nozzle enlargement could decrease the printing
Table 3 Slicing orientation simulations for one shell

\begin{tabular}{llllll}
\hline Configuration & \multicolumn{2}{l}{$\begin{array}{l}\text { Single extruder; 0.4 mm } \\
\text { nozzle; full supported }\end{array}$} & & \multicolumn{2}{l}{$\begin{array}{l}\text { Single extruder; } 0.8 \mathrm{~mm} \\
\text { nozzle; full supported }\end{array}$} \\
\cline { 2 - 3 } \cline { 5 - 6 } Angle (degrees) & $\begin{array}{l}\text { Mean } \\
\text { print time } \\
\text { (hh:mm) }\end{array}$ & $\begin{array}{l}\text { Material } \\
\text { usage } \\
(\mathrm{g})\end{array}$ & & $\begin{array}{l}\text { Mean } \\
\text { print time } \\
\text { (hh:mm) }\end{array}$ & $\begin{array}{l}\text { Material } \\
\text { usage } \\
(\mathrm{g})\end{array}$ \\
\hline 90 & $18: 39$ & 160 & & $07: 26$ & 191 \\
80 & $18: 15$ & 153 & & $07: 30$ & 184 \\
70 & $17: 43$ & 147 & & $07: 13$ & 177 \\
60 & $17: 00$ & 141 & $06: 51$ & 163 \\
50 & $16: 00$ & 132 & $06: 37$ & 157 \\
40 & $15: 32$ & 130 & $06: 47$ & 159 \\
30 & $15: 17$ & 132 & $07: 27$ & 171 \\
20 & $17: 10$ & 142 & $07: 37$ & 179 \\
10 & $16: 51$ & 145 & $07: 36$ & 182 \\
0 & $17: 00$ & 146 & $07: 30$ & 184 \\
\hline
\end{tabular}

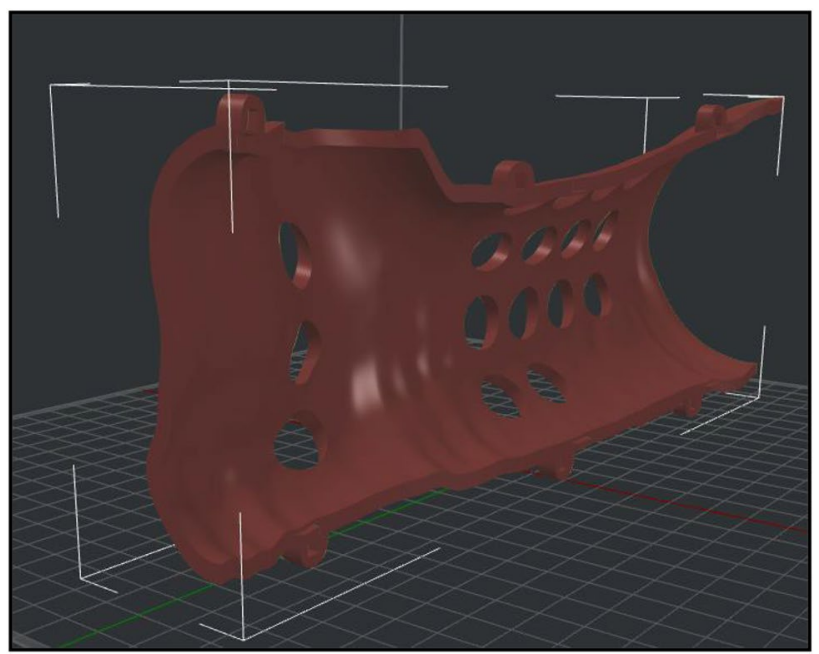

Fig. 11 Printing main direction

time up to $12 \mathrm{~h}$ maintaining mechanical characteristic of medical device even an increasing of used added material.

Table 4 shows the overall time saved phase by phase. Pre-processing and processing time, showed in the
Table 2 Processing phases design timing comparison

\begin{tabular}{llll}
\hline Manual procedure A & Timing (mm:ss) & Semiautomatic Procedure B & Timing (mm:ss) \\
\hline Mesh offset (A.4) & $03: 00$ & Surface reconstruction (B.c) & $00: 30$ \\
Shells generation (A.5) & $10: 00$ & & \\
Shells split (A.6) & $00: 20$ & Cast generation (B.d) & $01: 40$ \\
Shells engrave (A.7) & $45: 00$ & & \\
Internal and external locker (A.8) & $30: 00$ & & \\
Print orientation (A.9) & $05: 00$ & Total processing time & $02: 10$ \\
Total processing time & $93: 20$ & & \\
\hline
\end{tabular}


Table 4 Overall process time saved

\begin{tabular}{|c|c|c|c|}
\hline Step & $\begin{array}{l}\text { Manual procedure } \\
\text { (hh:mm) }\end{array}$ & $\begin{array}{l}\text { Semi- } \\
\text { automatic } \\
\text { procedure } \\
\text { (hh:mm) }\end{array}$ & $\begin{array}{l}\text { Time } \\
\text { saved } \\
\text { (hh:mm) }\end{array}$ \\
\hline Pre-processing & $00: 11$ & $\sim 00: 01$ & $00: 10$ \\
\hline \multirow[t]{2}{*}{ Processing } & 01:33 & $\sim 00: 03$ & 01:30 \\
\hline & $\begin{array}{l}\text { Best } 0.4 \mathrm{~mm} \text { nozzle } \\
\text { time }\end{array}$ & $\begin{array}{l}\text { Best } 0.8 \mathrm{~mm} \\
\text { nozzle } \\
\text { time }\end{array}$ & \\
\hline Print & $18: 28$ & 08:05 & $10: 23$ \\
\hline Total time saved & & & $12: 03$ \\
\hline
\end{tabular}

previous Tables 1 and 2, were converted from minutes to hours to match with printing time dimension.

This procedure overcomes the critical issues related to the time between the data acquisition and the installation of cast due to design and printing time, and the poor level of reproducibility of a manual CAD processing.

\section{Discussion and comparison}

The introduction of a workflow designed to meet requirements of an industrial approach is crucial to transfer the results of research into daily clinical practice. This requires the definition of a robust workflow [1] and the creation of a user-friendly graphical interface [2].

The procedure here presented allows to reduce elaboration and production time (about $12 \mathrm{~h}-95 \%$ for design and $55 \%$ for printing), and to increase the traceability of the process and the device. The use of Grasshopper ${ }^{\circledast}$ plug-in allows several advantages as save time, static production process, increase the repeatability, give more control and traceability on the process, etc. However, remain some crucial points solved with a light interaction by the user through simple number sliders and toggle switch.

The process so defined was able to produce a cast with length of $25 \mathrm{~cm}$, in about $10 \mathrm{~h}$, with a low-cost FDM printer, easy to use and maintain.

Even the paper is focused on production workflow and stops at print, the entire process (including material control, post processing and final testing) is compliant with standard guide lines for 3D [10,12]. The scan report, measurement check, the final report of design phase file is returned by the semiautomatic procedure to be inserted in the technical file of the device. These reports (and the entire workflow) respect the traceability principle of upto-date rules [11] in force from May 26th 2021 for CE mark of medical devices.

\section{Conclusion}

Starting from clinical experience $[5,13]$ the final aim of the present work was to develop a systematic procedure for the CAD modelling process for the production of $3 D$ patient-specific orthosis useful in clinical course to be extended other 3D clinical applications. At moment, this procedure allows to

1. Transfer the entire process in the clinical practice at the Unit of Orthopaedic at Santobono- Pausilipon Paediatrics Hospital and test it for production of several devices for the treatment of fractures especially in emergency.

2. Build up a controlled and verified industrial production line aimed to the production of 3D printed patient specific and adaptable medical devices for orthopaedics and other medical applications according to [10].

Acknowledgements This work was developed in the framework of a larger 3D project in medicine by Santobono Pausilipon Foundation. Alfredo Vacca was in charge for quality system design.

Funding This work was developed in the framework of "Campania Start Up" Grants from Regione Campania for innovative start up (CUP B62C18000470007) financed to Santobono Innovation srl.

\section{Declarations}

Conflicts of interest The authors declare that they have no conflict of interest.

Open Access This article is licensed under a Creative Commons Attribution 4.0 International License, which permits use, sharing, adaptation, distribution and reproduction in any medium or format, as long as you give appropriate credit to the original author(s) and the source, provide a link to the Creative Commons licence, and indicate if changes were made. The images or other third party material in this article are included in the article's Creative Commons licence, unless indicated otherwise in a credit line to the material. If material is not included in the article's Creative Commons licence and your intended use is not permitted by statutory regulation or exceeds the permitted use, you will need to obtain permission directly from the copyright holder. To view a copy of this licence, visit http://creativecommons. org/licenses/by/4.0/.

\section{References}

1. Li J, Tanaka H (2018) Rapid customization system for 3D-printed splint using programmable modeling technique - a practical approach. 3D Print Med. https://doi.org/10.1186/ s41205-018-0027-6

2. Paterson A, Donnison E, Bibb R, Campbell RI (2014) Computeraided design to support fabrication of wrist splints using 3D printing: a feasibility study. Hand Therapy 19:102-113. https:// doi.org/10.1177/1758998314544802 
3. Buonamici F, Furferi R, Governi L, Lazzeri S, McGreevi KS, Servi M, Talanti E, Uccheddu F, Volpe Y (2019) A CAD-based procedure for designing 3D printable arm-wrist-hand cast. Comput Aided Des 16(1):25-34. https://doi.org/10.14733/cadaps.2019.25-34

4. Gorski F, Kuczko W, Weiss W, Wichniarek R, Zukowska M (2019) Prototyping of and individualized multi-material wrist orthosis using fused deposition modelling. Adv Sci Technol Res J 13(4):2019. https://doi.org/10.12913/22998624/113543

5. Guida P, Casaburi A, Busiello T, Lamberti D, Sorrentino A, luppariello L, D'Albore M, Colella F, Clemente F (2019) An alternative to plaster cast treatment in a pediatric trauma center using the CAD/CAM technology to manufacture customized threedimensional-printed orthoses ina totally hospital context: a feasibility study. J Pediatr Orthop B 28(3):248-255. https://doi. org/10.1097/BPB.0000000000000589

6. Lin $\mathrm{H}$, Shi L, Wang $\mathrm{D}$ (2016) A rapid and intelligent designing technique for patient-specific and 3D-printed orthopedic cast. 3D Print Med 2:4. https://doi.org/10.1186/s41205-016-0007-7

7. Lunsford C, Grindle G, Salatin B, Dicianno BE (2016) Innovations with 3-dimensional printing in physical medicine and rehabilitation: a review of the literature. PM R 8(12):1201-1212. https:// doi.org/10.1016/j.pmrj.2016.07.003

8. Chen YJ, Lin H, Zhang X, Huang W, Shi L, Wang D (2017) Application of 3D-printed and patient- specific cast for the treatment of distal radius fractures: initial experience. 3D Print Med. 3(1):11. https://doi.org/10.1186/s41205-017-0019-y

9. U.S. department of health and human services food and drug administration (FDA), center for devices and radiological health, center for biologics evaluation and research. (2016) Technical considerations for additive manufactured medical devices; guidance for industry and food and drug administration staff. May 10, 2016.

10. International organization for standardization -ISO (2016). ISO 13485 medical devices -- quality management systems -- requirements for regulatory purposes (2016) (ISO, Geneva, Swizerland)

11. Regulation (EU) $2017 / 745$ of European parliament and of council of 5 April 2017 on medical devices, 2017.

12. Italian association of clinical engineers - AllC. (2021) Guidelines: additive manufacturing technologies in healthcare (in Italian), March 2021

13. Arulmozhi RS, Vaidya M, Pooljalakshmmi MG, Kumar DA, Anuraag $\mathrm{K}$ (2018) 3d design and printing of custom-fit finger splint. Biomed Eng 30(5):1850032. https://doi.org/10.4015/S1016 237218500321

14. Gopu G. (2016) Fabrication of fracture aid using rapid prototyping. proceedings of the 2016 international conference on industrial engineering and operations management Kuala Lumpur, Malaysia, March 8-10,

15. Wonseuk C, Wanho J, Jongbae K, Jeong-Hyun K, Subin H. (2018) A pilot study for usefulness of customized wrist splint by thermoforming manufacturing process using 3D printing: Focusing on comparative study with 3D scanning manufacturing process. resna annual conference.

16. Fitzpatrick AP, Mohanned MI, Collins PK, Gibson I (2017) Design of a patient specific. The international conference on design and technology, KEG, D printed arm cast. https://doi.org/10.18502/ keg.v2i2.607

17. Chu CH, Wang IJ, Sun JR, Liu CH (2020) Customized designs of short thumb orthoses using 3D hand parametric models. Assistive Technol 32:1-8. https://doi.org/10.1080/10400435.2019. 1709917

18. Boyd AS, Benjamin HJ, Asplund C (2009) Principles of casting and splinting. Am Fam Physician 79(1):16-22

19. Inglis M, McClelland B, Sutherland L, Cundy P (2013) Synthetic versus plaster of Paris casts in the treatment of fractures of the forearm in children: A randomised trial of clinical outcomes and patient satisfaction. Bone Joint J 95(9):1285-1289. https://doi. org/10.1302/0301-620X.95B9.30666

20. Egol KA, Walsh M, Romo-Cardoso S, Dorsky S, Paksima N (2010) Distal radial fractures in the elderly: operative compared with nonoperative treatment. J Bone Joint Surg Am 92(9):1851-1857. https://doi.org/10.2106/JBJS.I.00968

21. Williams KG, Smith G, Luhmann SJ, Mao J, Gunn JD 3rd, Luhmann JD (2013) A randomized controlled trial of cast versus splint for distal radial buckle fracture: an evaluation of satisfaction, convenience, and preference. Pediatr Emerg Care 29(5):555-559. https://doi.org/10.1097/PEC.0b013e31828e56fb

22. Delasobera BE, Place R, Howell J, Davis JE (2011) (2011) Serious infectious complications related to extremity cast/splint placement in children. J Emerg Med 41(1):47-50. https://doi.org/10. 1016/j.jemermed.2010.05.031

23. Halanski M, Noonan KJ (2008) Cast and splint immobilization: complications. J Am Acad Orthop Surg 16(1):30-40. https://doi. org/10.5435/00124635-200801000-00005

24. Ezair B, Massarwi F, Elber G (2015) Orientation analysis of 3D objects toward minimal support volume in 3D-printing. Comput Graph 51:117-124. https://doi.org/10.1016/j.cag.2015.05.009

Publisher's Note Springer Nature remains neutral with regard to jurisdictional claims in published maps and institutional affiliations. 